\title{
English Language as a Requirement Course for Information Students -- A Content Analysis of English Syllabus in the Faculty of Arabic and Islamic Studies/ Nile Valley University
}

\author{
Mustafa Shazali Mustafa Ahmed \\ Nile Valley University, Sudan \\ E- Mail: mustafashazali65@gmail.com
}

\begin{abstract}
The study investigated the importance of two elements in the process of syllabus design (ends / means specifications, program implementation) in the faculty of Islamic and Arabic studies, Nile Valley University, designed in 1995.Results indicate that the ends/means specifications stage is used to present the general aims and the objective of each course. A general description of each course is also given. Program implementation is completely left for the teacher's decision. The paper shows related literature review for information students. This kind of literature review (linguistic contents) may however change the Program Implementation to a highly individualistic and subjective stage. Materials writing are left only for teachers and this may cause variations in the linguistic contents of the prescribed courses and this in turn may lead to many hidden syllabuses. Teachers training as a unique step in program implementation stage is lacking since there is no ESP teacher program available
\end{abstract}

Keywords: Felt needs, Perceived needs, Program implementation, Material writing, Needs Analysis, Ends Specifications

\section{Introduction:}

The ministry of high education in Sudan has decided that university English requirements should be taught in 8 credits. By the end of the second year these credit must be taught and examined. What has been required from student in the past few years is just to pass successfully the requirements. This has recently been changed to calculate the grade point average of these requirements. The change in calculating the unit values of these requirements might have been decided to increase the students' motivation, although in fact you can make your students more motivated by using other learning techniques. So what is the philosophy behind taking such a decision? I leave it as an open question. The different specializations in the one faculty are always taught these requirements together in one classroom. This situation might, however, change or reduce these requirements to a kind of common core English. University requirement units which have recently been established in some Sudanese universities have designed English syllabuses not different from student previous English language school - curriculum to be taught as English requirements for the different departments. This has posed the following questions:

Who has participated in these designs?

What resources of information and expertise that has been available?

Who is responsible for formalizing the outcomes as a syllabus document the university or the ministry of high education?

Can such a program be considered as a coherent curriculum which can be exposed to maintenance and renewal?

What has been hypothesized in this paper is that there is no causal relationship between university English requirements as an intervention or independent variable and the students' improvement in their subject - related disciplines (as a dependent variable). For internal validity of this hypothesis the three criteria suggested by Lazarsfeld (1959) are met. the first is that the cause(requirement program) precedes the effect (students standards) in time. The second is that the two variables are empirically correlated to each other. The third is that there is no third variable that influences the process of teaching these requirements. The three criteria are met because the program implementation of these requirements has been conducted in the faculty of Islamic and Arabic Studies. Many questions will arouse in the coming literature review. One of the important questions is which is better for specifying validly the target communicative competence of the learners, the felt needs or the perceived needs ? Sudan mainly depends upon the judgments of the certified experts (normative or objective needs) to decide about the materials. The paper is questioning the probability of the English teacher to decide about the following : when design a syllabus can the English teacher focus on the knowledge offered in the materials, view of what is involved in the materials, decide about values and attitudes, cognitive abilities of the different students, and the role relations within the classroom. Materials need the process of rethinking, supplementing or abandoning. How can this be attained by the teacher alone? So reading my literature review will show you the subjectivity of needs definition.. Needs - based syllabuses are of controversial issue and it needs alternative philosophies of planning. 
Most English courses materials in Sudan have been written and are writing by English teachers alone. This, however, leads us to the main question in this paper which is do other countries design their students' materials the same way.

\subsection{Methodology:}

Data are collected through carefully investigating the previous syllabus designed by specialized committee in 1995. An approach of content analysis has shown that the ends and means specifications level as a second stage of decision has been achieved (appendix). The third stage of program implementation has not sufficiently planned. Teaching materials pertain to students related disciplines has been proved to be of great importance to the pedagogy of ESP. The coming part of this paper shows how does writing materials need to pursue a kind of literature review in the related field. The coming literature review is itself can be considered as descriptive or exploratory approach to this kind of unobtrusive observation about writing to the media. This kind of literature review affords mutually consistent and complementary answer to the question of what resources of information and expertise that must be available when designing the syllabus. Many answers to our questions can be hinted or extracted from this type of literature pertaining to media writing and its rules. Data were compiled from the historical documents of the syllabus designed in the faculty of Islamic and Arabic Studies/Nile Valley University. The data were used to answer properly the posed questions of this paper. The participants who have undergone this experiment were all English teachers. What has been done was only the second stage of curriculum development which is ends /means specifications (Appendix). The third stage of program implementation of curriculum development is completely left for the teachers .teachers should select linguistic contents , vocabulary ,grammar, notions, functions and $\mathrm{s} / \mathrm{he}$ should grade the syllabus in whatever way s/he thinks appropriate for his students. What is needed is a kind of planning which caters much for learners consideration, knowledge consideration, instructional and management considerations as designed by Rodgers(1980). Rodgers later on (1983) called this kind of planning polity determination. Rodgers' polity planning framework which is based on the four mentioned factors discusses, evaluates every kind of a syllabus. That is the four considerations give the planners the chance for negotiations the strengths and weaknesses of the suggested syllabus. This may however turn the process of design a syllabus to multi-dimensional, qualitative, interactive, and participants-extended options. Thus what has been done by the specialized committee is likewise what has been done by Munby(1978).In his attempt to design communicative syllabus, Munby has constructed a system from which syllabus content can be derived. What the specialized committee has done is just specifying ends and means leaving the whole process of decision -making for the teachers. How can contextual constraints be decided by the English teacher, and how can these constraints be organized by a teacher alone. How could the teacher decide about time, energy and money. How can s/he co -ordinate the selected materials.

\section{Literature Review (Selected Linguistic Contents)}

\subsection{Reporting the News as a Process of Communication:}

Language symbols alone have no meaning, but their real meaning is usually included in their referential kind of items, or to the event which they stand for, as stated by Anderson et. al. (1964, P .90), and what the referent of a word means, depends on the individual's experience with that word. This leads to what is called the word's literal meaning (denotations), and intentional meaning (connotations) which sustain greatly the analysis of the nature of the lexicon. Therefore, the process of communication is always thought of as intrapersonal communication (within the self), and interpersonal one (between two or more people), (Grunder et. al, 1977, P. 20).

Most essential to note is that communication process is regarded as a complex process, because it has so many angles shared together in order to produce and interpret a message. Giffin \& Patton's (1971, P.45), assume that there are six people involved whenever there is communication. The first is the person you think yourself to be. The second one is the man your partner thinks you are, and the third is the person you believe your partner thinks you are. Plus the three equivalent persons are those at the end of the circuit. That is the same three persons on behalf of your partner's view.

This supports Davison's (1976, PP.71 - 76) assumption that different newspapers may offer different versions of the same event, since each one represents a different political climate. Moreover, journalistic content in general is greatly influenced by the audience's attitudes towards what is offered by the newspaper.

Defleur \& Dennis (1981, P. 137) distinguish between newspapers and magazines. They claim that a magazine is published less frequently; manufactured in a different format usually on better quality paper, bound rather than just folded, and with some kind of cover. Besides that magazines usually tend to tackle topics in broader perspectives.

According to differences in cultures various political climates, news gathering agencies are criticized in looking forward to objective, straight, factual reporting, irrespective with determining associated meanings through analyzing facts. This leads editors like Erwin Canham to claim that the "background, surrounding circumstance prior events motivation - all are part of the real and basic news" Rivers (1964, P. 180). Here, this kind of interpretation is actually the best kind of reporting. That is knowledge of a situation is the vital element in interpreting reporting. This also leads to know how media content or foreign news supplied by wire services might be killed, rewritten, or transmitted further because of the 
internal local pressures of a particular community, and sources that make and control decisions. This is clearly investigated in Watson \& Hill's (1997, PP. 4 - 91) terms of 'agenda setting' and gatekeeper.

There is also what is called the alternative journalist who is usually thought of as being neutral. The advocacy journalist is one who writes always with a commitment to a particular view point, (Emery \& Smythe, 1972, PP.120-25).

It can be assumed then that a journalist as an individual may have a political position which might be influenced and interpreted through the expectations and ideology which guide his political behavior (Mueller, 1973, P.101).

\subsection{Technicalities of Writing Feature Headlines:}

In most notable newspapers headlines are always written by copy editors who " "stand midway between the reporter and the editor', (Rivers 1964, P .288). They are intended to capture the attention of the reader; give gist of the story, grade the news symbolically, attract and hold the attention of the reader to the particular article (Duff \& Shindler, 1984, PP. 424).

Rivers (1964, PP. 288 - 295) suggests certain criteria for writing a headline. The first is that headlines or 'heads' must be deduced or rendered out of the information that appears in the first few sentences of a newstory. These first sentences are called the 'leads', and defined by Rivers (ibid, P. 156) as that kind of sentences which include the five Ws (who, what, when, where and why), and which explain the how as well. Hamilton\& Krimsky, (1996, P. 51) call this phenomenon the immutable journalistic law of the five Ws and $\mathrm{H}$.

Journalists also tend to relate events in chronological order. That is events are described in descending order of importance. The first short opening sentences give the gist of the whole story, using the technique of the five ' $W$ ' and " $H$ '. This process of ordering is known in journalism by the inverted pyramid which is considered for a long time as the standard form for presenting news. The five Ws and H are exemplified by Rivers' (1964, P .167), as follows.

HOLLYWOOD- A police detective was shot to death Sunday when he and a companion were Kidnapped on HOLLYWOOD BLVD, and forced to derive two ex-convicts 60 miles. (Rivers, 1964: 167)

The second criteria of writing a headline as (Rivers, 1964, P .167) indicated is that 'heads' must be written in present tense so that it can give a reader a sense of immediacy. See also Duff\& shindler, (1984, P .4).

Heads must also contain a verb, either expressed or implied. Verbs forms must be written, exception is only permitted in some editorials. The following examples are taken from Rivers.

Faculty Codifies Absence Rules:

The above example shows that verb-form is recommended rather than the nouns-form.

Regulations for absences:

It is to note here that verb 'to be' and the articles ' $a$ ', 'an' and 'the' are always omitted in headlines. Exception to this is made only if they are essential to real meaning of the head. for example:

Actor found dead:

(Duff, Shindler, 1984, P .4).

In the above example if 'articles', and the' verb to be' are included, the headline will appear as the follows.

An actor has been found dead:

Heads also are written in the active voice, rather than the passive so that ambiguity can be removed. The future is expressed in heads by the form of the future tense, or the infinitive form, or the present tense with a date. Example:.

MP to open health centre:

(Duff, Shindler, 1984, P. 4)

Rivers (1964) also provides miscellaneous rules of writing headlines. These rules can be stated, as not to separate parts of a verb, or proper nouns between lines. Verb - first - form is avoided, and instead a noun - first - form is used. Also one does not separate the preposition and its object, and not to separate an adjective and the word it described. Also generally a 'comma' is used in a place of 'and'. And one should not repeat the same word twice. Well known abbreviations are always used to save space and time. Finally all first letters in lines must be capitalized, and all the principle words.

Many devices are used in writing features headlines, but punning of words is considered to be the most common one. Devices that can be included are Rhyme, Alliteration, twisted cliché, and allusions. As, for puns, Christ (1982, P. 4 - 8) assumes that because of the oddities of English spelling puns are much found and can easily be made up.

Hamilton \& Krimsky (1996, PP. 47 - 61) illustrates that the age of big, bold, brassy headlines is now dying. However, more emphasis has been given to the total page design and packaging of news. That if the information is so compelling a 
good story writes itself. Therefore, and in order to provide examples of headlines, Duff \& Shindler (1984, P. 8) are recommending the following example which shows how a journalist writes economically.

Council budget axed:

Journalists always leave out words that do not add to the content like the articles, verb to be' prepositions. Thus nouns are always piled together. But, in a future passive form 'verb to be' is used as in the following example.

Health centre to be opened by MP:

Also, there are times in which nouns can not be piled and prepositions can not be left out as in the following example.

Model killed by doctor:

Nurse in village killing:

Puns or (playing with meaning) can also be done on words with different meanings where each meaning is vital to the particular story. Example of this is the following headline.

It's the sole clue:

The above headline shows a story where the sole clue to who had carried out a theft was on the sole of a shoe.

It also can be played on words of the same pronunciation, and which have different spellings, and therefore different meanings, but each is essential to the story. Example of this would be the following headlines.

Weight for it:

In this story a man has to wait before he can collect winnings from a bet concerning his weight.

Rhyming also appears in words which echo each other's sound. Example of this is the following.

Greater Crater:

Alliteration is used in words which start with the same letter or sound. Example to this is the following.

Channel champion:

Duff \& Shindler (1984, P.5) concluded by saying that, whenever one is looking at headlines that play with language, he may find that some of the connections may be rather loose. Hence, one should use his imagination to grasp the intended meaning. That is one does not expect the precision of a dictionary. However, this can be replaced by that one must use appropriate pragmatic inferences to carry out the meaning of these codes, or headlines.

Duff \& Shindler (ibid) further state that the reporter can convey his $\backslash$ her meanings in formal or conversational style. They provide the following examples to illustrate this.

Mr Smith became interested in Vaccination:

John took a fancy to a jab ...

Thus, the reporter has many tools to use in determining his style. S $\backslash \mathrm{He}$ can use humor, irony or literary devices and reference words or juxtaposition of ideas. Example of this juxtaposition of ideas would be the following.

I didn't vote in the local elections this Year. None of the candidates appealed to me.

Essential to note here is that this journalistic technique of 'juxtaposition of ideas', can be replaced by Widdowson's (1979) linguistic analysis by two - level propositions which appears in the following example.

The unions refused to accept the government's proposal. Unemployment has been rising steadily over the past few months.

Here, Widdowson (1979) indicates that at the level of form, there are two separate sentences, and at the content level, there are two separate propostions. That is the second sentence proposition explains the state of affairs described in the first sentence, since, that sentence propositions usually satisfy conditions which identify different communicative acts.

\subsection{Writing Feature:}

In writing features, the reporter usually reacts positively or negatively to the life around him. Features are highly individualistic, and are considered as vehicles of opinion (Rivers, 1964, P. 185).

In defining what feature is, the answer would be all the published materials in the papers are considered features with exception to editorial, reviews and opinion columns. Rivers (1964) adds that feature writer must often judge, and should never advocate. Furthermore, features differ from stories in that they are always factual. They are divided in human interest issues; interviews, sport reporters and family affairs. For a question within an interview and multifunctionality of utterances as speech acts Schiffrin, (1994, PP.14- 85). 


\subsection{Communication Problems:}

Most essential to note here is that when sending a letter or a message, the communication process should entail no physical, physiological impairment or psychological problems Berko,( 1977, P.10 - 13). By physical is meant, the outside interference or noise that blocks the receiver from hearing the message, and physiological impairment is used to describe biological flaws such as deafness in people who do not have the sensory capabilities to receive a message, unless they use some mechanical devices. Semantic problems which usually include cultural difference may hinder understanding. Example of semantic problems is represented by foreign diplomats who are assigned to American embassies in Washington. Those diplomats always translate the word "catsup" (tomato sauce), at the verb "catch up". Syntactic problems always include the message encoded without grammar - rules. Example of this is a two year old girl who says 'milk'. This word can not be interpreted in a good sense unless its context of situation is identified. Therefore, it may mean 'I don't want the milk', or I want a glass of milk'.

Rivers (1964) indicates that precise writing in journalism entails removal of what is called vague language. Although, sentences like "boy are supposed to be Boys", "you can not find anyone over thirty", which are exemplified by Berko (1977) are considered as social noise or problems, but pragmatic theory may provide reasonable interpretation to such kind of sentences.

Here, it is important to note term of vague additives to such kind of repetition. They are exemplified by Rivers (1964) as in the following words:

Dead body

body

New innovation

innovation

Future Plans

plans

Canary bird

canary

Invited guests

guests

They are described by Ferguson (1980) as "identical twin". Example of this is the following.

Our mayor is lifelong native of our city.

Freguson (1980) shows that the above sentence should be rewritten like the following.

Our mayor is a native of our city.

Another example is

Please save this list for future reference.

Please save this for reference.

Finally it can be said that such concepts of vague language always lead editors to correct errors of grammar. And be so precise in judging news values; look for the right word; remove the unnecessary words (empty words) as preferred by Freguson (1980). Editors must also bear special attention to moveable parts such as 'almost', 'even', 'hardly', 'just', 'merely', 'never', 'rarely', and the confusing pronouns (Freguson, 1980, P 7).

-Editors should cater for Lyons' (1977) assumption that statements usually express propositions which are in turn reflecting the writer's attitudes and behaviors. He notes that much of the information that is conveyed from speaker to addressee in conversation is implied rather than asserted.

Watson \& Hill (1997, P.54) name the item which may influence the way in which messages are encoded or decoded as cultural capital. They define it as knowledge, tastes, attitudes, values and assumptions which individual or groups possess in response to various cultures.

This cultural capital can be represented as the journalist's or editor's or newspaper's attitudes towards the propositions which are chosen to be written or stated, thus, this cultural capital will be catered for in interpreting or reading journalistic texts .

Competence is used to mean what the speaker of the language knows implicitly however, what $\mathrm{s} / \mathrm{he}$ really does is considered as his performance. To instance for that, we find that the traditional grammar does not actually formulate the rules of grammar, but instead it affords examples and hints that determine the grammar. Chomsky's generative grammar on the other hand goes beyond the view of traditional grammar by giving attention to what is called 'creativity of language' (Allen \& Burn 1971, P.2). Notwithstanding, it has widely been agreed that the general problem appears in corresponding form to meaning. That is, the distinction made between what is said and what is meant. Levinson (1983) confirms that one can 'read in' an utterance more than what it conventionally means. That is to say, one can say something to indicate something else. 


\section{Conclusions}

3.1 Materials writers and teacher trainers have not fully practiced the role assigned for them when designing the syllabus of the faculty of Islamic and Arabic Studies

3.2 Hidden syllabuses were formed because of the variations of the linguistic contents chosen by teachers. That is the specialized committee has left the teacher in the mid way to decide about how to implement the ends /means specifications that have already been identified.

3.3 Media as ESP has many idiosyncrasies and different style of writing .There should be a unanimous agreement by all the planners about the syllabus linguistic contents. This stage of program implementation has not found enough consideration by the specialized committee which has been selected to the assigned job.

\section{References}

Allen, J. P. B and B. U Burn (eds). (1971). Chomsky: selected Reading. Oxford: Oxford University press.

Anderson, R. (1995). On the Logical integrity of children's argument. U. S. Ilionis: Centre for the study of reading Urbana, TL

Breko, W. (1977). Communication: A Social and Career Focus. Boston Houghton Mifflin Company.

Christ, H. (1982). Modern English in Action, Tornonto. D. C. Health and Company Press.

Davidson, W. J. and J. C Boylan. (1976). Mass Media Systems and Effects. New Your. Holt, Rinehart and Winston.

Duff, B. and R Shindler. (1984). Language and Style in the Press. London: Collins ELI

Emery, M. and T. Smythe. (1972). Reading in Mass Communication: Concepts and Issues in the Mass Media. Doubuque, Lowa: Willaiam C. Brown Company.

Ferguson, P. (1980). 30 Lessons in Editing for A Reader. New York: curriculum Associates.

Giffin, K. and B Patton (ed). (1971). Basic Reading in Interpersonal Communication. New York: Harper and Row.

Grunder, C. D. Freshley, R Huseman. (1977). Speech Communication in Society, London: Allyn and Bacon.

Hamilton, J. and G. Krismsky. (1996). Hold the press. The Inside Story on Newspaper. Baton Rouge and London: Louisiana State University Press.

Lazarsfeld,P. (1959). Problems in Methodology in Robert,K.Merton(ed) Sociology Today. Newyork:Basic Books

Levinson, S. C. (1983). Pragmatics. Cambridge. Cambridge University Press.

Lyons, J. (1977). Deixis and Anaphora. In T. Myers (eds) The Development of conversation and Discourse. Edinburgh: Edinburgh University Press.

Mueller, C. (1973). The Politics of communication Study in the political sociology of language, socialization, and legitimating. London: Oxford University Press.

Munby,J. (1978). Communicative syllabus Design .Cambridge: Cambridge University Press

Rivers, W. (1964). The Mass Media: Reporting, Writing and Editing. New York Harper and Row.

Rodgers,T.S. (1980). Materials Development in Prospect.ELT Documents Special- Projects in Materials Design. London. The British Council 164-71.

Schiffrin, D. 1990, Approaches to Discourse. Oxford UK and Cambridge USA Blackwell.

Watson J. and A. Hill. (1997). A Dictionary of Communication and Media Studies. London: Arnold.

Widdowson A. G. (1979). Exploration in Applied Linguistics, Oxford: Oxford University Press.

\section{Appendix}

Nile Valley University

Faculty of Islamic \& Arabic Studies

Ends \& Means Specifications (Reviewed by Specialized Committee Common Core English

First year

Objectives .
A. To develop the language four skills with special emphasis on Reading.
B. To reinforce English grammar and pronunciation contextually.
C. To develop basic study skills e.g. dictionary use. 


\section{Course Description}

The course will include texts of general interests and subject related texts. These texts will act as sources of generating communicative activities, and in that sense grammar will be taught implicitly. The learners are encouraged to develop the basic study skills e.g. Informational transfer, paragraph writing and dictionary use (Oxford Learner's Dictionary is recommended)

\section{ESP General Aims,}

(Second - fourth year)

a) To develop students' communicative abilities through carefully selected Islamic texts.

b) To increase the learners' vocabulary subject related disciplines.

c) To introduce and practice translation at all levels i.e. phrase - sentence, texts.

d) To understand and practice Arabic transliteration.

Information Department

Second year

Course Description.

ESP

ESP

201

202

Written and spoken texts are selected from Islamic propagation and media (Journalism broadcasting, TV.) Students are encourage to communicate orally in the field mentioned above. In this context grammar, pronunciation, transliteration are thoroughly practiced. Translation is introduced at a sentence level.

Third year

ESP ESP

$301 \quad 301$

Students are exposed to authentic texts from the various means of communication (media). Students are trained in the propagation and journalistic techniques e.g. editing. Translation is practiced at a paragraph level.

Fourth year

ESP

ESP

401

401

Students will be exposed to advanced text. Students are made aware of the distinctive features of these texts e.g. headlines. Type size,eye catch effect. Translation is practiced on longer texts. Towards the end of the eighth semester students should be able to give oral presentation on topics related to their studies. 